\title{
ВПЛИВ ЗОВНІШНЬОГО ШУМУ ЛЕГКОВОГО АВТОМОБІЛЯ НА ДОВКІЛЛЯ
}

\begin{abstract}
Розглянуто питання впливу транспортного шуму на довкілля. Проведено порівняння шумового поля легкових автомобілів марки Renault. Запропоновано раціональне шумове поле та показник спрямованості легкового автомобіля, що підвищує безпеку учасників дорожнього руху.

Встановлено шумове поле автомобіля Renault Symbol i запропоноване раціональне шумове поле, для формування якого необхідне: дотримання допустимого рівня шуму на відстані 7,5 м від поздовжньої осі автомобіля; забезпечення підвищеної спрямованості шуму вздовж напряму руху, як чинник додаткового інформування пішоходів і водіїв про наближення автомобіля для забезпечення їх безпеки; забезпечення різного показника спрямованості з правої чи лівої сторони автомобіля залежно від організації дорожнього руху (правосторонній чи лівосторонній рух).

На підставі аналізу отриманого шумового поля можна стверджувати, що на розподіл рівня шуму навколо автомобіля Renault Symbol найбільший вплив має двигун. Рівень шуму від випуску відпрацьованих газів на шумове поле має менший вплив, ніж шум власне двигуна.

Таким чином, понизити загальний рівень шуму автомобіля, без зниження рівня його джерела, можна завдяки перерозподілу енергії шуму справа наліво і в напрямку руху (назад і вперед).

Ключові слова: шумове поле, автомобіль, рівень шуму, безпека учасників дорожнього руху, показник спрямованості.
\end{abstract}

Постановка проблеми. Автомобільний транспорт має велике значення для народного господарства України. Він $є$ достатньо конкурентоспроможним порівняно 3 іншими видами транспорту, а в деяких галузях - домінуючим. Крім позитивних характеристик автомобілі мають, i негативні, однією, з яких є шумове забруднення довкілля $[3,7]$.

Шум автомобілів негативно впливає на здоров'я людей, особливо у містах [15]. Зменшити шум у місті найдоцільніше, перш за все, зменшенням рівня шуму міського транспорту. В останні роки спостерігається зростання потужності двигунів автомобілів, підвищення їх швидкості руху i зростання чисельності автомобільного парку $[4,12,18,19$ ] одночасно із впровадженнями конструктивних заходів щодо зниження шуму транспортних засобів актуальною є проблема боротьби 3 шумом, що поширюється цими засобами у зовнішнє середовище. Світові тенденції характерні і для міст України через невпинне зростання парку легкових автомобілів, який за прогнозом міністерства інфраструктури України до 2020 року буде в 2 рази більшим, ніж у 2000 році. Тенденція зростання рівня шуму є характерною для вулиць великих міст України. Наприклад, рівень шуму на перехресті вулиці Городоцької і проспекту Чорновола в центрі Львова під час рушання 3 місця автомобілів становив 90 дБА, що значно перевищує допустимий (65 дБ А) рівень згідно національної нормативної бази $[14,16]$. Тому проблема шумового навантаження автомобілями довкілля стає все більш актуальною.

Аналіз останніх досліджень. На думку ряду вчених $[1,4,9,11,13,19]$ в процесі руху автомобіля ним випромінюється шум, що створюється двигуном, агрегатами трансмісії автомобіля, кузовом (під дією двигуна, дороги і потоку повітря), зменшення впливу якого можливе, наприклад, заміною бетонного покриття асфальтовим, встановленням вздовж магістралей шумоізолюючих екранів, чи примусовим зниженням швидкості руху автомобілів. Разом 3 тим, шум залишається проблемою вздовж швидкісних магістралей і в населених місцях. Деякі вчені $[12,17]$ впевнені, що знизити шум від транспорту в містах за допомогою традиційних методів достатньо складно і це вимагає суттєвих капіталовкладень. Більш доступнішим видається контроль і зниження шуму від безпосередніх джерел його виникнення - автомобілів.

Формування цілей роботи. Метою роботи є вивчення впливу шуму легкових автомобілів на довкілля. У боротьбі із шумом найдоцільнішим способом $\epsilon$ зниження його рівня безпосередньо в джерелі утворення, в нашому випадку, рівня шуму, що генерується від автомобілів. Тому метою досліджень була побудова шумового поля автомобіля та визначення раціонального показника спрямованості.

Основна частина. За об'єкт дослідження зовнішнього шуму був прийнятий легковий автомобіль фірми Renault, моделі Symbol, ключовими характеристиками, якого є надійність, низька 
ціна і невисокі витрати на експлуатацію [8]. Дослідження проводились згідно загальноприйнятих [2, $5,6,10,20]$ і розроблених методик [13] за допомогою шумоміра ВШВ-003-М2 3 похибкою вимірювань $\pm 0,7$ дБ. Для вимірювання частоти обертання колінчастого вала двигуна використовувався тахометр панелі приладів автомобіля Renault Symbol з діапазоном вимірювань (0$7000)$ об/хв., 3 граничною похибкою $(-50-+300)$ об/хв. Для вимірювання швидкості вітру був використаний прилад ANEMO виробництва Німеччини, 3 діапазоном вимірювання 0-35 м/с, граничною похибкою $\pm 0,5 \mathrm{~m} / \mathrm{c}$ і ціною поділки $1 \mathrm{~m} / \mathrm{c}$.

Простір, в якому розповсюджуються хвилі, називається полем [12]. Шумовим полем автомобіля вважають розподіл інтенсивності шуму навколо нього під час стоянки і роботи двигуна на певному режимі. Шумове поле автомобіля (рис. 1) визначалося на основі результатів замірів рівня шуму в 12-и точках навколо автомобіля на відстані 1 м від його зовнішньої поверхні на висоті 1,2 м від поверхні, при цьому двигун працював без навантаження за частоти обертання колінчастого вала 4500 об/хв.

Аналізуючи характер отриманого шумового поля можна стверджувати, що на розподіл рівня шуму навколо автомобіля Renault Symbol найбільший вплив має двигун. Рівень шуму в точках 12,1 , 2, на 7-11 дБ А вищий, ніж в точках $6,7,8$. Шум від випуску відпрацьованих газів на шумове поле має менший вплив, ніж шум власне двигуна.

Також досліджувалось шумове поле для інших моделей Renault (за цих же умов), з різним об'ємом двигуна - Dacia Logan 1,6 модель 3 двигуном К7M710 з робочим об'ємом $1600 \mathrm{~cm}^{3}$, Laguna 3 двигуном F4P770 з робочим об'ємом $1800 \mathrm{~cm}^{3}$ (рис. 2). Дані вимірювань підтверджують гіпотезу, що збільшення робочого об'єму двигуна зумовлює збільшення рівня звуку автомобіля у всіх точках шумового поля.

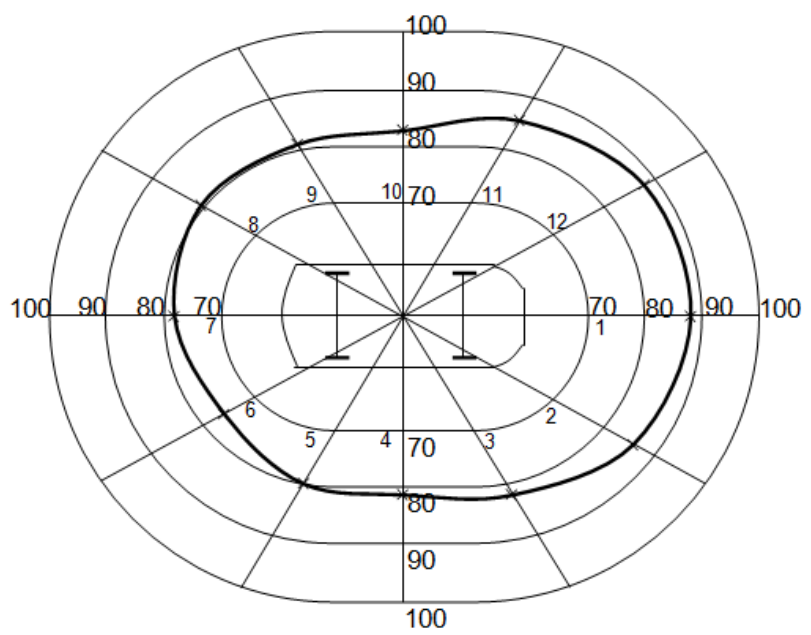

Рисунок 1. Шумове поле автомобіля Renault Symbol

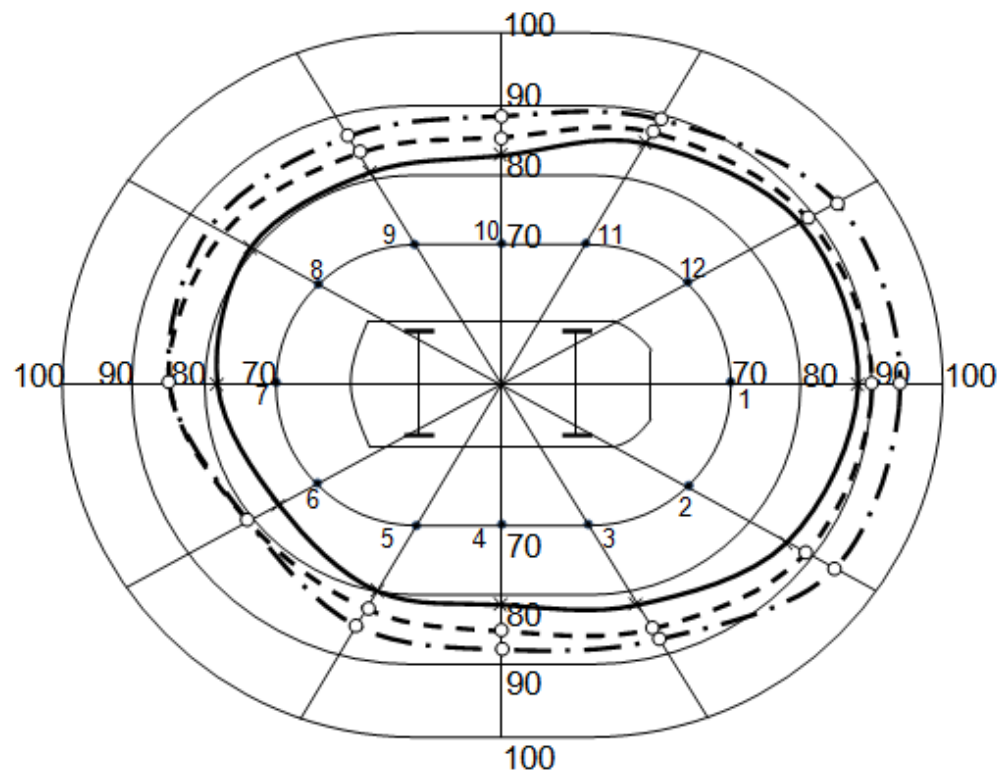

Рисунок 2. Шумове поле моделей автомобілів Renault з робочим об'ємом: — Symbol (1400 $\left.\mathrm{cm}^{3}\right) ;$ - - - Dacia Logan $\left(1600 \mathrm{~cm}^{3}\right) ;--$ Laguna $\left(1800 \mathrm{~cm}^{3}\right)$ 
Проаналізувавши шумові поля і спектри шуму, одержані під час руху автомобіля, можна стверджувати, що випромінювання шуму автомобіля, що вліво, що вправо від осі руху практично однакові. Незаперечно, що за правостороннього руху пішоходи і житлові споруди розташовуються 3 правого боку автомобіля. Ця обставина, враховуючи, що шумове поле має симетричний характер, збільшує звукове навантаження на них. Подібна закономірність властива і випромінюванням шуму вперед-назад. Тому важливим видається розв'язання питання про раціональне шумове поле автомобіля, яке б враховувало не тільки допустимий рівень шуму, але і організацію дорожнього руху i інформативність про наближення автомобіля до перехресть. Сформувати таке поле можна завдяки перерозподілу випромінюваної звукової енергії акустичними екранами, не вдаючись до глушіння шуму, що є надто дорогим. Запропоноване раціональне шумове поле вимагає розподіл рівня шуму навколо автомобіля, сформованого, виходячи 3 трьох передумов: дотримання допустимого рівня шуму на відстані 7,5 м від поздовжньої осі руху автомобіля; підвищена спрямованість звуку у напрямку руху, як додаткова інформація про наближення автомобіля, що убезпечує пішоходів $\mathrm{i}$ водіїв; різний показник спрямованості з лівого чи з правого боку автомобіля залежно від організації дорожнього руху (лівосторонній чи правосторонній рух).

У випадку перерозподілу звукової енергії автомобіля Renault Symbol справа наліво і у напрямку руху (назад і вперед) отримаємо рівень шуму під час руху на відстані 7,5 м від поздовжньої осі автомобіля з лівого боку 73 дБ А (точка 10), а з правого боку - 69 дБ А (точка 4), попереду - 97,2 дБА (точка 1), а позаду - 97,2 дБА (точка 7) (рис. 3). Таким чином раціональне шумове поле побудоване емпіричним шляхом.

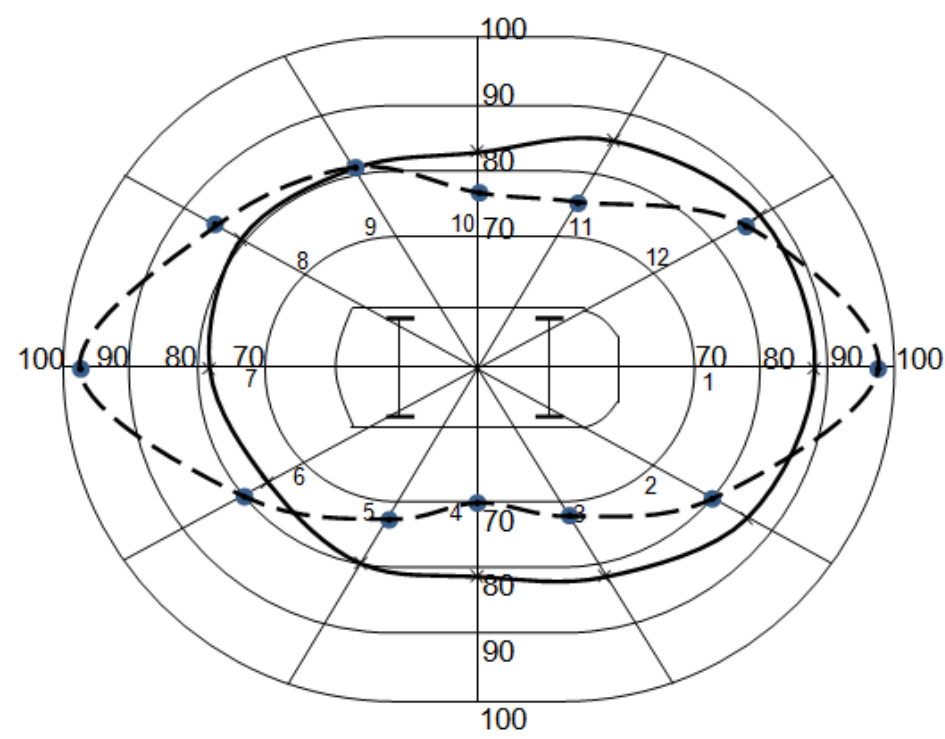

Рисунок 3. Виміряне (-) шумове поле автомобіля Renault Symbol і запропоноване раціональне (- - - ).

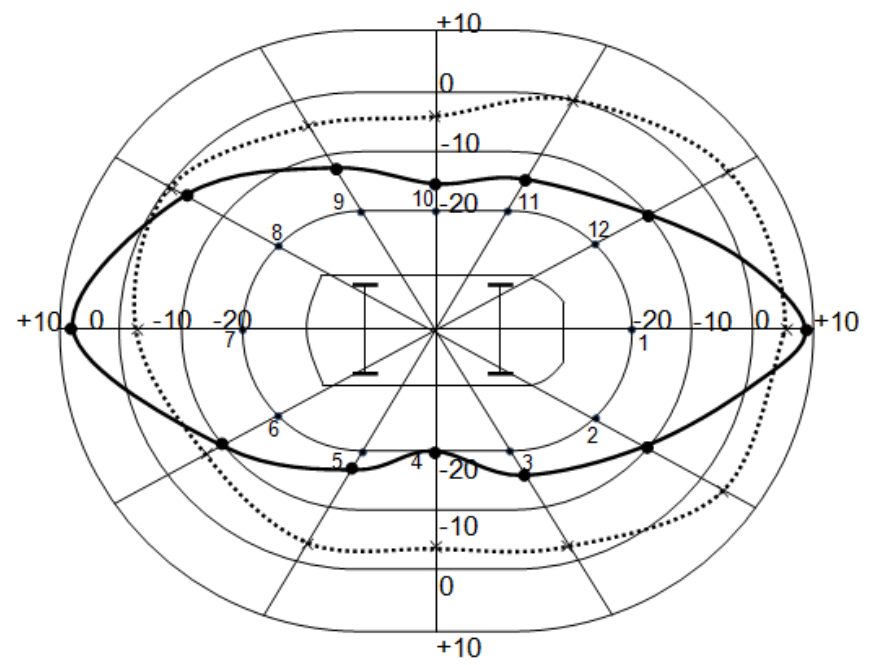

Рисунок 4. Показник спрямованості рівня шуму автомобіля Renault Symbol на відстані 7,5 м: - - - експериментальні дані;

- •- раціональний показник спрямованості. 
Під показником спрямованості ПС розуміють різницю між середнім рівнем звуку в дБ(А) і значенням рівня в заданому напрямі і заданій точці, що розташована на відстані опорного радіусу. Опорний радіус - це відстань від досліджуваної точки до центру джерела шуму.

На рис. 4 представлена діаграма показника спрямованості звукового рівня шуму автомобіля Renault Symbol. 3 рисунка видно, що спрямованість шуму попереду автомобіля (точки 1, 2, 11, 12) більша за інших, що пояснюється розташуванням попереду двигуна, шум якого спрямовується через передні і нижні відкриті отвори решітки радіатора, позаду спрямованість менша.

Провівши перерозподіл звукової енергії автомобіля Renault Symbol, можна отримати раціональний показник спрямованості (рис. 4).

Необхідно зазначити про наступне:

1. Більша спрямованість звуку у напрямі руху автомобіля (точки 1,7$)$ сприяє додатковому інформуванню пішоходів і водіїв про наближення автомобіля, забезпечуючи їх безпеку.

2. Різні значення показників спрямованості з правого (т.4) і лівого (т.10) боку автомобіля пояснюється правостороннім рухом в Україні, і намаганням зменшити спрямованість звуку на пішоходів.

Висновки. Встановлене шумове поле автомобіля Renault Symbol і запропоноване раціональне шумове поле, для формування якого необхідне: дотримання допустимого рівня шуму на відстані 7,5 м від поздовжньої осі автомобіля; забезпечення підвищеної спрямованості шуму вздовж напряму руху, як чинник додаткового інформування пішоходів і водіїв про наближення автомобіля для забезпечення їх безпеки; забезпечення різного показника спрямованості з правої чи лівої сторони автомобіля залежно від організації дорожнього руху (правосторонній чи лівосторонній рух).

Таким чином, понизити загальний рівень шуму автомобіля, без зниження рівня його джерела, можна завдяки перерозподілу енергії шуму справа наліво і в напрямку руху (назад і вперед).

1. Barrelet S. Development and refinement for the sound package of the new Renault Clio 3 / S Barrelet, T Laurent, K Trdak Rieter Automotive Conference, 2005

2. Балабин И.В. Испытания автомобилей: Учебное пособие. / И.В. Балабин, Б.А. Куров, С.А. Лаптев - М.: Машиностроение, 1988. - 192 с.

3. Васильева В.В. Автотранспортный шум в городах и его влияние на окружающую среду / В.В. Васильева // Мир транспорта и технологических машин -2010.- №3(30) - С.101-107.

4. Вопросы шума при взаимодействии шины с дорогою / [В.А. Карпенко, В.А. Перегон, А.Н. Левченко, А.А. Коряк] // Вестник Харьковского национального автомобильно-дорожного университета. - 2015. - № 71. - С. 109-111.

5. ГОСТ 27436-87. Внешний шум автотранспортных средств. Допустимые уровни и методы измерений. - М.: Стандартиздат, 1987. - $13 \mathrm{c.}$

6. ДСТУ 3649:2010 «Колісні транспортні засоби. Вимоги безпеки до технічного стану та методи контролю» -К.: Мінекономрозвитку України, 2010. - 11 с.

7. Качмар Р.Я. Оцінювання екологічних та економічних втрат від шуму транспортних потоків міста Львова / Р.Я.Качмар // Автомобільний транспорт: дослідження. - Львів. -№1(231) - 2013. - С. 10-13.

8. Кисуленко Б.В. Краткий автомобильный справочник. Том 3. Легковые автомобили. Ч.2. / Кисуленко Б.В. -М.: НПСТ «Трансэконсалтинг», 2004. - 560 с.

9. Куновский Э.Б. Идентификация источников шума автомобіля / Э.Б. Куновский - Минск: Технопринт, $2005 .-324$ с. Кушвид Р.П. Испытания автомобиля: учебник / Р.П. Кушвид - М.: МГИУ, 2011. - 351 с.

10. Leasure W.A. Tire-road interaction noise / W.A. Leasure, E.K. Bender - America: 1975. - P.39-50 (J. Of Acoustical Society of America: July. - V. 58/ - №1).

11. Луканин В.Н. Снижение шума автомобиля / В.Н. Луканин, В.Н. Гудцов, Н.Ф. Бочаров - М.: Машиностроение, 1981. -243 c.

12. Миронюк О.С. Дослідження шумових характеристик плодознімального засобу / О.С. Миронюк //Вісник Львівського державного аграрного університету: Агроінженерні дослідження. - 2005. -№9. -С. 154-158.

13. Петренко О. Аналіз вимог чинних нормативно-правових актів щодо допустимих рівнів шуму і вібрації автомобіля / О. Петренко // Вісник НУ «Львівська політехніка». - 2013. - №753: Автоматика вимірювання та керування. - С. $152-158$.

14. Петренко О.К. Вплив шуму автомобільного транспорту на організм людини ІО.К. Петренко // Україна у європейському просторі. Проблеми бізнесу, політики, права: мат. VI Міжнар. наук.-практ. конф., Львівський університет бізнесу та права. - Львів, - 2010. - С. 46-48.

15. Петренко О.К. Контроль за станом шуму на центральних вулицях Львова / О.К. Петренко // Якість технологій та освіти. - Харків, 2011. - С.45-51.

16. Самойлюк Е.П. Борьба с шумом в населенных местах / Е.П. Самойлюк, В.И. Денисенко, А.П. Пилипенко - К.: Будівельник, 1981. - $144 \mathrm{c.}$

17. Факторович А.А. Защита городов от транспортного шума / А.А. Факторович, Г.И. Постников - К.: Будівельник, 1982. $-144 \mathrm{c}$.

18.Шатров М.Г. Шум автомобильных двигателей внутреннего сгорания: учеб. пособие / М.Г. Шатров, А.Л. Яковенко, Т.Ю. Кричевская. - М.: МАДИ, 2014. - 68 с.

19. Эллисон А. Измерение шума машин. / А. Эллисон. - М.: Энергоатомиздат, 1998. - 374 с. 


\section{REFERENCES}

1. Barrelet S. 2005. Development and refinement for the sound package of the new Renault Clio 3 / S Barrelet, T Laurent, K Trdak - Rieter Automotive Conference.

2. Balabin I.V. 1988. Testing of cars: Textbook. I.V. Balabin, B.A. Kurov, S.A. Laptev - M.: Mechanical Engineering, 192.

Vasilyeva V.V. 2010. Road noise in cities and its impact on the environment / V.V. Vasilyeva // The world of transport and technological machines. - № 3 (30). 101-107.

3. Questions of noise in the interaction of the tyre with the road / [V.A. Karpenko, V.A. Peregon, A.N. Levchenko, A.A. Koryak] // Bulletin of Kharkov National Automobile and Highway University. 2015. No. 71. 109-111.

4. GOST 27436-87. 1987. External noise of vehicles. Permissible levels and methods of measurement. - Moscow: Standardizdat, 13.

5. DSTU 3649: 2010. 2010."Wheeled vehicles. Safety requirements to the technical condition and methods of control" - K.: Ministry of Economic Development of Ukraine, 11.

6. Kachmar R.Ya. 2013. Estimation of environmental and economic losses from traffic noise in the city of Lviv / R.Ya.Kachmar // Automobile transport: research. - Lviv №1 (231). 10-13. 560 .

7. Kisulenko B.V. 2004. Brief automobile directory. Volume 3. Cars. Part 2. / Kisulenko B.V. - M.: NSTT "Transeconculting",

8. Kunovskiy E.B. 2005. Identification of car noise sources / EB. Kunovsky - Minsk: Technoprint, 324.

9. Kushvid R.P. 2011. Tests of the car: the textbook / R.P. Kushvid. - Moscow: MGIU, 351

10. Leasure W.A. 1975. Tire-road interaction noise / W.A. Leasure, E.K. Bender - America: 39-50.

11. Lukanin V.N. 1981. Reducing the noise of the car / VN. Lukanin, V.N. Gudtsov, N.F. Bocharov - M.: Mechanical Engineering, 243.

12. Mironyuk O.S. 2005. Investigation of the noise characteristics of the fruit-extractor / O.S. Mironyuk // Visnyk of Lviv State Agrarian University: Agroengineering research. - No. 9. 154-158.

13. Petrenko O. 2013. Analysis of the requirements of the current normative legal acts on permissible levels of noise and vibration of the car / O. Petrenko // Bulletin of the National University "Lviv Polytechnic". - № 753: Automation of measurement and control. 152-158.

14. Petrenko O.K. 2010. Influence of noise of motor transport on the human body \O.K. Petrenko // Ukraine in the European Space. Problems of business, politics, law: mat. VI International science-practice conference, Lviv University of Business and Law. Lviv, 46-48.

15. Petrenko O.K. 2011. Control over noise in the central streets of Lviv / O.K. Petrenko // Quality of technology and education. - Kharkiv, 45-51. 144.

16. Samoylyuk Е.P. 1981. Fighting noise in populated areas / Е.П. Samoylyuk, V.I. Denisenko, A.P. Pilipenko. - K.: Budivelnik,

17. Faktorovich A.A. 1982. Protection of cities from traffic noise / A.A. Faktorovich, G.I. Postnikov. - K.: Budivelnik, 144.

18. Shatrov M.G. 2014. Noise of automobile internal combustion engines: training. tb / M.G. Shatrov, A.L. Yakovenko, T.Yu. Krichevskaya. - M.: MADI, 68.

19. Ellison A. 1998. Measurement of the noise of machines. A. Ellison. - Moscow: Energoatomizdat, 374. среду.

Миронюк О.С., Шевчук В.В., Грабовець В.В. Влияние внешнего шума легкового автомобиля на окружающую

Рассмотрены вопросы влияния транспортного шума на окружающую среду. Проведено сравнение шумового поля легковых автомобилей марки Renault. Предложенное рациональное шумовое поле и показатель направленности легкового автомобиля способствуют повышению безопасности участников дорожного движения.

Ключевые слова: шумовое поле, автомобиль, уровень шума, безопасность участников дорожного движения, показатель направленности.

\section{Mironyuk O., Shevchuk V., Grabovets V. Noise load of a car on the environment.}

The questions of influence of transport noise on the environment are considered. A comparison of the noise field of passenger cars of Renault brand is made. Rational noise field and the direction index of a car, which increases the safety of road users is proposed.

We indicated the noise field of the Renault Symbol car and proposed a rational noise field, for which formation is required: adherence to the permissible noise level at a distance of $7.5 \mathrm{~m}$ from the longitudinal axis of the car; providing increased direction of noise along the direction of motion as a factor in additional informing pedestrians and drivers about the approach of the car to ensure their safety; providing different indicator of the direction of the right or left side of the car depending on the organization of traffic (right or left-hand traffic).

Analyzing the nature of the noise field obtained, it can be argued that the distribution of the noise level around the Renault Symbol has the greatest impact on the engine. The noise from the exhaust gases on the noise field has a lower effect than the noise of the actual engine.

Thus, reducing the overall noise level of a car without losing its source level can be achieved by redistributing noise energy from right to left and in the direction of motion (back and forth).

Keywords: noise field, car, noise level, safety of road users, direction index.

\section{АВТОРИ:}

МИРОНЮК Олег Сергійович, кандидат технічних наук, доцент кафедри «Автомобілів і тракторів», Львівський національний аграрний університет, e-mail: muronjuk@ukr.net

ШЕВЧУК Віктор Володимирович, кандидат технічних наук, доцент, завідувач кафедри «Автомобілів і тракторів», Львівський національний аграрний університет, e-mail: shevtyk@ meta.ua 
ГРАБОВЕЦЬ Віталій Валерійович, кандидат технічних наук, доцент кафедри «Автомобілів і транспортних технологій», Луцький національний технічний університет, e-mail:vgrabovets@ukr.net

АВТОРЫ:

МИРОНЮК Олег Сергеевич, кандидат технических наук, доцент кафедры «Автомобилей и тракторов», Львовский национальный аграрный университет, e-mail: muronjuk@ukr.net

ШЕВЧУК Виктор Владимирович, кандидат технических наук, доцент, заведующий кафедрой «Автомобилей и тракторов», Львовский национальный аграрный университет, e-mail: shevtyk@meta.ua

ГРАБОВЕЦ Виталий Валерьевич, кандидат технических наук, доцент кафедры «Автомобилей и транспортных технологий», Луцкий национальный технический университет, еmail: vgrabovets@ukr.net

AUTHORS:

Oleg MIRONYUK, Ph.D., in Engineering, Assoc. Professor of the Department of Cars and Tractors Of Lviv National Agrarian University, e-mail: muronjuk@ukr.net

Viktor SHEVCHUK, Ph.D., in Engineering, Assoc. Professor Head of the Department of Cars and Tractors Of Lviv National Agrarian University, e-mail: shevtyk@ meta.ua

Vitaliy GRABOVETS, PhD. in Engineering, Assoc. Professor of Motor Cars And Transport Technologies Department, Lutsk National Technical University, e-mail: vgrabovets@ukr.net 